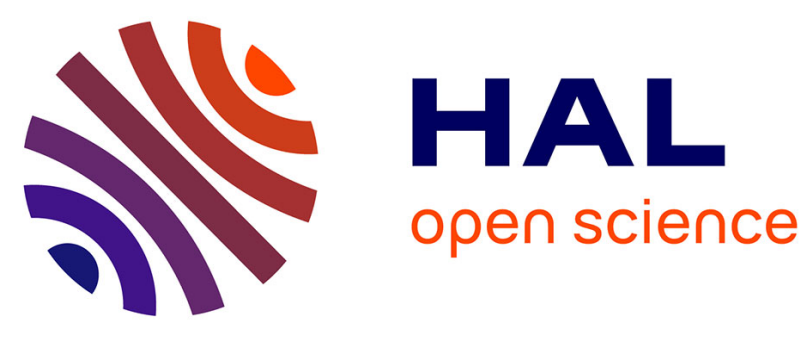

\title{
Design of 0-3 type nanocomposites using hydrothermal sintering
}

Arnaud Ndayishimiye, Sonia Buffière, Marie-Anne Dourges, Alain Largeteau, Mythili Prakasam, Stéphane Mornet, Ondřej Kaman, Jirák Zdeněk, Jiř́ Hejtmánek, Graziella Goglio

\section{To cite this version:}

Arnaud Ndayishimiye, Sonia Buffière, Marie-Anne Dourges, Alain Largeteau, Mythili Prakasam, et al. Design of 0-3 type nanocomposites using hydrothermal sintering. Scripta Materialia, 2018, 148, pp.15-19. 10.1016/j.scriptamat.2018.01.013 . hal-01708877

\section{HAL Id: hal-01708877 \\ https://hal.science/hal-01708877}

Submitted on 5 Mar 2021

HAL is a multi-disciplinary open access archive for the deposit and dissemination of scientific research documents, whether they are published or not. The documents may come from teaching and research institutions in France or abroad, or from public or private research centers.
L'archive ouverte pluridisciplinaire HAL, est destinée au dépôt et à la diffusion de documents scientifiques de niveau recherche, publiés ou non, émanant des établissements d'enseignement et de recherche français ou étrangers, des laboratoires publics ou privés. 


\title{
Design of 0-3 type nanocomposites using hydrothermal sintering
}

\author{
Arnaud Ndayishimiye ${ }^{1}$, Sonia Buffière ${ }^{1}$, Marie-Anne Dourges ${ }^{2}$, Alain Largeteau ${ }^{1}$, \\ Mythili Prakasam ${ }^{1}$, Stéphane Mornet ${ }^{1}$,Ondřej Kaman ${ }^{3}$,Jirák Zdeněk ${ }^{3}$,Jiří Hejtmánek ${ }^{3}$, \\ Graziella Goglio, ${ }^{1, *}$ \\ ${ }^{1}$ CNRS, Univ. Bordeaux, ICMCB, UMR 5026, 87 avenue du Dr A. Schweitzer, 33608 Pessac, France \\ ${ }^{2}$ ISM, UMR CNRS 5255, Univ. Bordeaux, 351 Cours de la Libération, 33405 Talence Cedex, France \\ ${ }^{3}$ Institute of Physics of the Czech Academy of Sciences, Cukrovarnická 10, 16200 Praha 6, Czech \\ Republic
}

Corresponding author: $\quad$ graziella.goglio@u-bordeaux.fr

Tel : +33 (0)540006334

Fax : + $33(0) 540002761$

\begin{abstract}
We report here the successful design of 0-3 type nanocomposites where $30 \mathrm{~nm}$ ferromagnetic metallically conducting cores of manganite $\mathrm{La}_{0.66} \mathrm{Sr}_{0.34} \mathrm{MnO}_{3}$ (LSMO) are discretely distributed in an

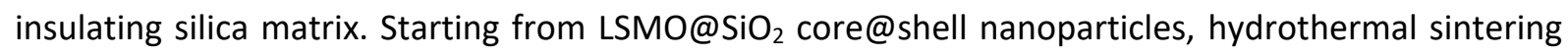
process was used as a low temperature densification route $\left(300^{\circ} \mathrm{C}, 350 \mathrm{MPa}, 90 \mathrm{~min}\right)$ in presence of $0.2 \mathrm{M}$ aqueous sodium hydroxide solution. This process based on a pressure solution creep in the contact zones between nanoparticles allows the design of complex microstructures preventing the grain growth of the cores and the formation of interphases between the cores and the matrix.
\end{abstract}

\section{Key words:}

Hydrothermal Sintering, Composites, Nanostructuration, Low-Temperature Water-Assisted Densification 
Advanced materials such as new high-performance composites are our allies for a sustainable future. For instance, the introduction of an insulating phase at the grain boundaries in polycrystalline metallically conducting manganites with ( $\mathrm{La}, \mathrm{Sr}) \mathrm{MnO}_{3}(\mathrm{LSMO})$ or ( $\left.\mathrm{La}, \mathrm{Ca}\right) \mathrm{MnO}_{3}(\mathrm{LCMO})$ compositions promotes the role of tunneling of spin-polarized carriers between neighboring perovskite grains [1-8]. Consequently, the macroscopic transport is strongly dependent on external magnetic field, and such composites are promising as elements with large negative magnetoresistance (positive magnetoconductance) for the design of spintronic devices. The development of these systems, mainly issued from the densification of mixtures of LSMO and insulating phase powders, is strongly dependent on the mastery of efficient sintering processes. However, the co-sintering is hindered by differences in thermal stability, the rate and the onset temperature of shrinkage, and the physical and/or chemical compatibilities between components. It has been claimed that classical thermal treatments may induce the evolution of the manganese oxidation state [9], the grain growth [10], the segregation of the insulating phase $[2,5,11,12]$ or the formation of an interphase between the two components (see supplementary material, part SM1). This difficult control of the microstructure and the formation of side phases may then have a detrimental influence on the magnetoconductive properties because the tunnel barrier structure becomes more complex and new spin-nonconserving conducting channels (spin-flip, thermally activated) are contributing.

We propose here a strategy based, on the one hand, on grain boundary engineering to design 0-3 type nanocomposites starting from core@shell nanoparticles and, on the other hand, on the implementation of a low temperature sintering process (see Figure 1). In this way, after sintering, LSMO cores are expected to be uniformly and discretely embedded in an insulating matrix of threedimensional-connectivity (3D) that originates from the silica shell densification. Here, silica also ensures the confinement of defects at the interfaces and should impede the core growth. This complex multimaterial microstructure is expected to be regular and tailored with a simultaneous control of the amount and of the chemical nature of tunnel barriers $[13,14]$. Hydrothermal sintering has been chosen as the low temperature densification route. Among the water-assisted densification routes such as cold sintering process CSP [15-18], water-assisted flash [19] or SPS [20] processes, hydrothermal sintering offers the specificity to operate in a close system, which promotes the diffusion of chemical species, hence of the reactivity. In this process, as in the CSP, the dissolution occurs in the contact zone between particles while the precipitation operates at the less stressed surface of particles, i.e. the pore surface. The involved solvent also acts as a mass transport medium and enhances creep at the grain/grain interface to promote densification [21-23]. It may be noted that, during sintering, water remains liquid and is expelled by densification in specific spaces for water removal $[21,23]$ while in Cold Sintering Process, the system is open and water evaporates. In the first case, the process is rather thermodynamically controlled while in the second one it is mainly controlled by kinetics, the predominance of the elementary steps depending on the closed/open system.

In this way, hydrothermal sintering appears as a powerful tool to favour the densification of silica, the shell being in contact with the solvent, while the manganite cores and the manganite/silica interfaces remain totally inert. This process based on mechanical-chemical mechanisms thus should ensure 
conditions that comply with the characteristics of the specifications. The purpose of this paper is then to provide a proof of concept for this nanostructuration strategy.

The manganite $\mathrm{La}_{0.66} \mathrm{Sr}_{0.34} \mathrm{MnO}_{3}$ (LSMO) nanoparticles with perovskite structure were synthesized using molten salt route. The silica coating of these as-obtained $30 \mathrm{~nm}$ LSMO nanoparticles was performed according to Stöber's method. The targeted shell thicknesses were 5 and $10 \mathrm{~nm}$, as-obtained

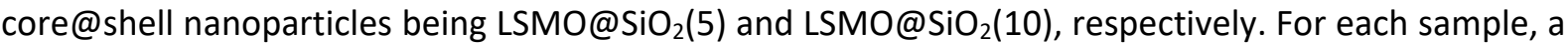
mixture of core@shell nanoparticles with $20 \mathrm{wt} \%$ of a $0.2 \mathrm{M}$ aqueous sodium hydroxide solution was prepared and shaped in the form of green pellets with $\approx 55 \%$ of compactness. The synthesis and

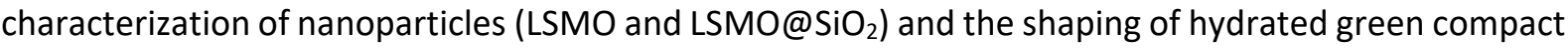
are described in the supplementary material, parts SM2 and SM3, respectively.

In the hydrothermal sintering process, a powder with water or a hydrated green compact is externally and mechanically compressed in an autoclave under hydrothermal conditions and over short periods of time. The solvent is expelled during densification and recovered in specific spaces for solvent retreat [21]. The experimental conditions implemented for the densification of composites were chosen identical to those we previously used for the densification of $50 \mathrm{~nm}$ silica nanoparticles, reaching $86 \%$ of relative density [21]. It was shown that the use of the mineralizer $\mathrm{NaOH}$ at low concentration promotes the dissolution of silica. In a first step, each hydrated green compact is subjected in the hydrothermal sintering device to a pressure increase up to $127 \mathrm{MPa}$ in order to avoid the vaporization of water during the subsequent heating of the system. The temperature is then increased up to $300{ }^{\circ} \mathrm{C}$ with a heating rate of $10^{\circ} \mathrm{C} / \mathrm{min}$. When the temperature reaches $150^{\circ} \mathrm{C}$, the pressure is increased, in 15 seconds, up to $350 \mathrm{MPa}$. The sample is maintained in the autoclave at $300^{\circ} \mathrm{C}$ under $350 \mathrm{MPa}$ for 90

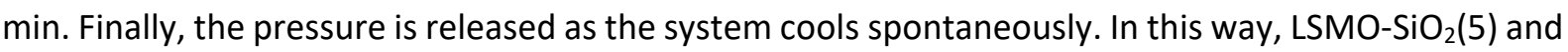
$\mathrm{LSMO}_{\mathrm{SiO}}(10)$ composites are obtained from starting silica shell thickness of 5 and $10 \mathrm{~nm}$, respectively. All characterization procedures are detailed in the supplementary material, part SM4. For the thinnest silica shell (Figure 2a), the as-obtained $\mathrm{LSMO}^{2} \mathrm{SiO}_{2}(5)$ composite exhibits a microstructure that consists of a cohesive assembly of well-faceted particles embedded in a vitreous matrix (Figure 2b). One can observe highly dense blocks where LSMO nanoparticles do not seem to be directly in contact with each other but whose morphologies are still distinct. Some small pores can be distinguished on the HR SEM image. Their nature is confirmed by the mercury intrusion porosimetry measurements that reveal the mesoporous nature of the composite (Figure $2 c$ ) as the pore size ranges from 10 to $30 \mathrm{~nm}$. Considering the basic mechanisms involved, the initial mesopores originating from the compact assembly of core@shell nanoparticles in the green material are gradually filled by precipitation. The residual presence of small mesopores in the composite thus reveals that the progression of densification has been incomplete. The relative density is evaluated at $83 \pm 5 \%$. For the

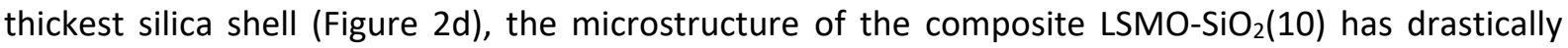
evolved (Figure 2e). In this case, some larger pores are distributed in a highly dense homogeneous matrix. On the left bottom of figure $2 \mathrm{e}$, one can observe that, as expected, LSMO cores are uniformly and discretely embedded in a three-dimensional-connectivity silica network. The mercury intrusion porosimetry measurements show that the material is predominantly macroporous with a maximum 
pore size of $200 \mathrm{~nm}$. However, around 12 vol\% of mesopores still contribute to the total porosity. The relative density is evaluated at $77 \pm 5 \%$. We can conclude that, when the silica shell thickness increases, the densification mechanisms are more efficient as they promote the filling of the initial mesopores. However, this densification propagation involves also a rapid release of water that was accommodated in the microstructure via the formation of macropores, hence leading to a decrease of the relative density. One can reasonably formulate the hypothesis that the different microstructures of LSMO$\mathrm{SiO}_{2}(5)$ and $\mathrm{LSMO}^{-\mathrm{SiO}_{2}}(10)$ originate from the difference of compressibility between the manganite and the silica. The compressibility strongly influences the stress gradient (induced by external uniaxial compression) within particles and consequently the activation of dissolution/precipitation phenomena.[22] The thicker the silica shell is, the more the core@shell particles densify similarly to pure silica nanoparticles, the formation of macropores facilitating the rapid water release in compressible materials, as we previously observed on $50 \mathrm{~nm} \mathrm{SiO}{ }_{2}$ nanoparticles $[22,23]$.

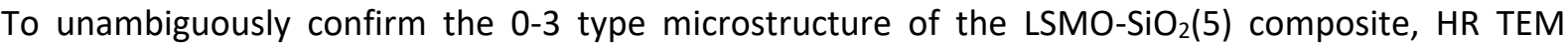
characterization has been performed (Figures 3a-b). The microstructure is homogeneous and shows that highly crystalline manganite nanoparticles are individually embedded in an amorphous matrix. The average distance between the crystallized cores equals 2-2.5 nm, far from the initial distance before sintering $(10 \mathrm{~nm})$. This impressive decrease of the inter-core distance is due (i) on the one hand, to the polycondensation of native silanol groups in the shells which induces a contraction of silica [22] and (ii) on the other hand, to the mass transport of silica from the inter-grain contact zones towards neighboring pores that are gradually filled by precipitation. The decrease of the inter-core distance hence confirms the efficiency of the hydrothermal sintering process. The chemical nature of both the crystallites and silica matrix was studied with STEM-EDS measurements (Figures $2 \mathrm{c}-\mathrm{g}$ ). It can be clearly observed that silicon is only present in the amorphous gangue whereas manganese, lanthanum and strontium are concentrated in the crystalline cores. The morphology of these cores does not seem to be significantly changed by the hydrothermal sintering treatment. Hence, considering also the element distribution and the high resolution images, one can reasonably conclude that the hydrothermal sintering has allowed, as expected, to prevent the formation of interphases between LSMO and silica. Finally, to highlight the inertia of the manganite cores during the sintering, X-ray diffraction (XRD)

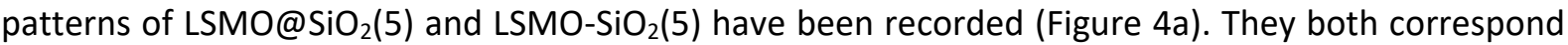
to well-defined perovskite structure with rhombohedral symmetry described in a hexagonal cell, the peaks being indexed in R-3c space group. The peak widths are consistent with nanosized crystallites. Considering that neither the peak widths nor their positions and intensities evolve after the sintering as the insert of Figure 4a clearly shows, it can be deduced that the size and composition of LSMO crystallites remain constant during the hydrothermal sintering. Moreover, the evolution of the inverse

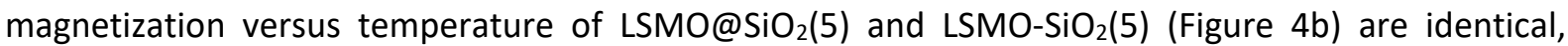
particularly in the high temperature regime. As the slope of the Curie-Weiss line above the Curie temperature does not change significantly after sintering, we can consider that the oxidation state of manganese remains constant during the densification. 
As a first example of electronic transport and magnetoconductive properties of the present products, the resistivity of the $\mathrm{LSMO}^{-\mathrm{SiO}_{2}}$ (5) composite is given in Figure 4c (insert). Note that the roomtemperature value, $10^{5} \Omega \cdot \mathrm{cm}$, is to six orders of magnitude larger than the resistivity of nanogranular La $_{0.53} \mathrm{Sr}_{0.47} \mathrm{MnO}_{3}$ ceramics prepared by spark plasma sintering of bare molten salt grown nanoparticles [24] and to eight orders of magnitude larger than the intrinsic LSMO resistivity. There is a strong localization toward low temperatures, but the dependence in Arrhenius plot is not linear, indicating a gradual decrease of activation energy with its possible vanishing at lowest temperature. Let us note that the low-temperature limit $d(\operatorname{In} \rho) / d(1 / T) \rightarrow 0$ is expected for quantum mechanical tunneling between metallically conducting LSMO cores. Finally, the isothermal resistivity scans taken up to high magnetic fields have been evaluated in terms of relative magnetoconductance ratio $M C=$ $\left(\sigma(H)-\sigma_{0}\right) / \sigma_{0}$, where $\sigma_{0}$ and $\sigma(\mathrm{H})$ are the conductivities without and under applied field $\mathrm{H}$, respectively (see Figure 4c). Concerning the $\mathrm{LSMO}^{-\mathrm{SiO}_{2}}(10)$ composite, this material is too resistive for similar DC resistivity characterization. However, it may represent a great interest for broadband dielectric spectroscopy in a search for composite materials that exhibit giant permittivity [25].

To summarize, we have developed a bottom-up strategy based on the grain boundary engineering to design 0-3 type composites. The implementation of hydrothermal sintering makes the cores inert with respect to the densification mechanisms, neither their grain growth nor their participation in the formation of interphases being observed while the embedding silica matrix drastically condensates. Obviously this strategy can be extended to many other systems to tune their thermoelectric or multiferroic properties for example.

\section{References}

[1] Z.C. Xia, S.L. Yuan, W. Feng, L.J. Zhang, G.H. Zhang, J. Tang, L. Liu, S. Liu, G. Peng, D.W. Niu, L. Chen, Q.H. Zheng, Z.H. Fang, C.Q. Tang, Solid State Commun. 128 (2003) 291

[2] W.J. Lu, Y.P. Sun, X.B. Zhu, W.H. Song, J.J. Du, Mater. Lett. 60 (2006) 3207

[3] A. Gaur, G.D. Varma, J. All. Comp. 453 (2008) 423

[4] C.S. Xiong, Y. Zeng, Y.H. Xiong, J. Zhang, Y.B. Pi, L. Zhang, J. Xiong, X.W.Cheng, F.F.Wei, L.J.Li, Physica B 403 (2008) 3266

[5] P.T. Phong, N.V. Khiem, N.V. Dai, D.H. Manh, L.V. Hong, N.X. Phuc, Mater. Lett. 63 (2009) 353

[6] D. K. Petrov, L. Krusin-Elbaum, J.Z. Sun, C. Field, P.R. Duncombe, Appl. Phys. Lett. 75 (1999) 995

[7] L. E. Hueso, J. Rivas, F. Rivadulla, M.A. Lopez-Quintela, J. Appl. Phys. 89 (2001) 1746

[8] D. T. Tran, T.H. Nguyen, H.M. Do, D.L. Vu, T.L. Phan, S.C. Yu, Adv. Nat. Sci. : Nanosci. Nanotechnol. 4 (2013) 035001

[9] J. Mitchell, D. Argyriou, C. Potter, D. Hinks, J. Jorgensen, S. Bader Phys. Rev. B - Condens. Matter Mater. Phys. 54 (1996) 6172 
[10] P.A.Yadav, A.V. Deshmukh, K.P. Adhi, B.B. Khale, N. Basavaih, S.I. Patil, J. Magn. Magn. Mater. 328 (2013) 86

[11] M. Eshraghi, H. Salamati, P. Kameli, J. Phys. : Condens. Matter 18 (2006) 8281

[12] A. Gaur, G.D. Varma, Solid State Commun. 139 (2006) 310

[13] H. Yang, Z.E. Cao, X. Shen, T. Xian, W.J. Feng, J.L. Jiang, Y.C. Feng, Z. Q. Wei, J. F. Dai, J. Appl. Phys. 106 (2009) 104317

[14] J. Koktan, G. Goglio, J, J. Hejmánek, Z. Jirák, K. Knížek, J. Kuličkova, M. Maryško, O. Kaman., IEEE Trans. Magn. 53 (2017) 8109606

[15] H. Guo, A. Baker, J. Guo and C.A. Randall, ACS Nano, 10 (2016) 10606-10614

[16] J. Guo, H. Guo, A.L. Baker, M.T. Lanagan, E.R. Kupp, G.L. Messing and C.A. Randall, Angew. Chemie - Int. Ed., 55 (2016) 11457-11461

[17] H. Guo, A. Baker, J. Guo, C.A. Randall and D. Johnson, J. Am. Ceram. Soc., 99 (2016) 3489-3507

[18] A. Baker, H. Guo, J. Guo and C. Randall, J. Am. Ceram. Soc., 99 (2016) 3202-3204

[19] J. Nie, Y. Zhang, J. M. Chan, R. Huang, J. Luo, Scripta Mater. 142 (2018) 79

[20] J. Gonzalez-Julian, K. Neuhaus, M. Bernemann, J. Pereira da Silva, A. Laptev, M. Bram, O. Guillon, Acta Mater. 144 (2018) 116

[21] G. Goglio, A. Largeteau, A. Ndayishimiye, M. Prakasam, French patent, submission number 1000405429

[22] A. Ndayishimiye, A. Largeteau, S. Mornet, M. Duttine, M-A.Dourges, D. Denux, M. Verdier, M. Gouné, T. Hérisson de Beauvoir, C. Elissalde, G. Goglio, J. Eur. Cer. Soc.,DOI 10.1016/j.jeurceramsoc.2017.10.011 (in press)

[23] A. Ndayishimiye, A. Largeteau, M. Prakasam, S. Pechev, M-A. Dourges, G. Goglio, Scripta Mater. 145 (2018) 118

[24] Z. Jirák, J. Hirschner, O. Kaman, K. Knížek, P. Levinský, M. Maryško, J. Hejtmánek, J.Phys.D, Appl.Phys. 50 (2017) 075001

[25] T.J. Lewis, J. Phys. D: Appl. Phys. 38 (2005) 202. 


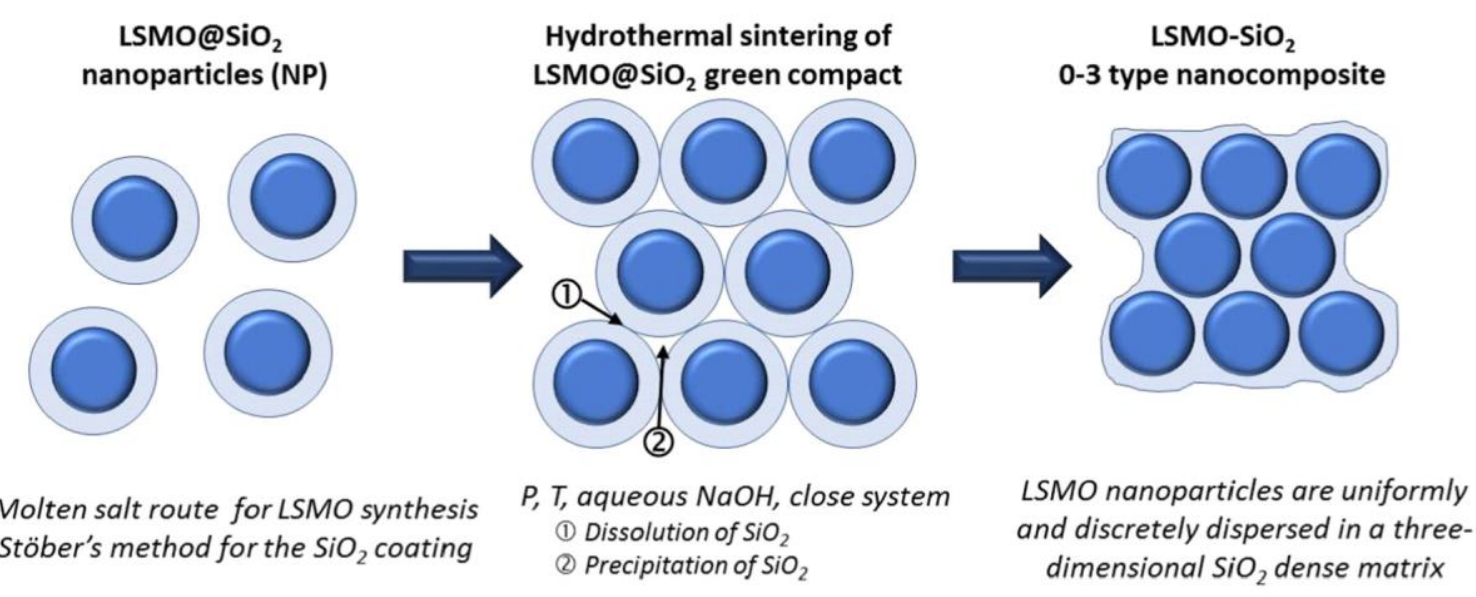

Fig. 1. Bottom up strategy deployed for the fabrication of 0-3 type composite.
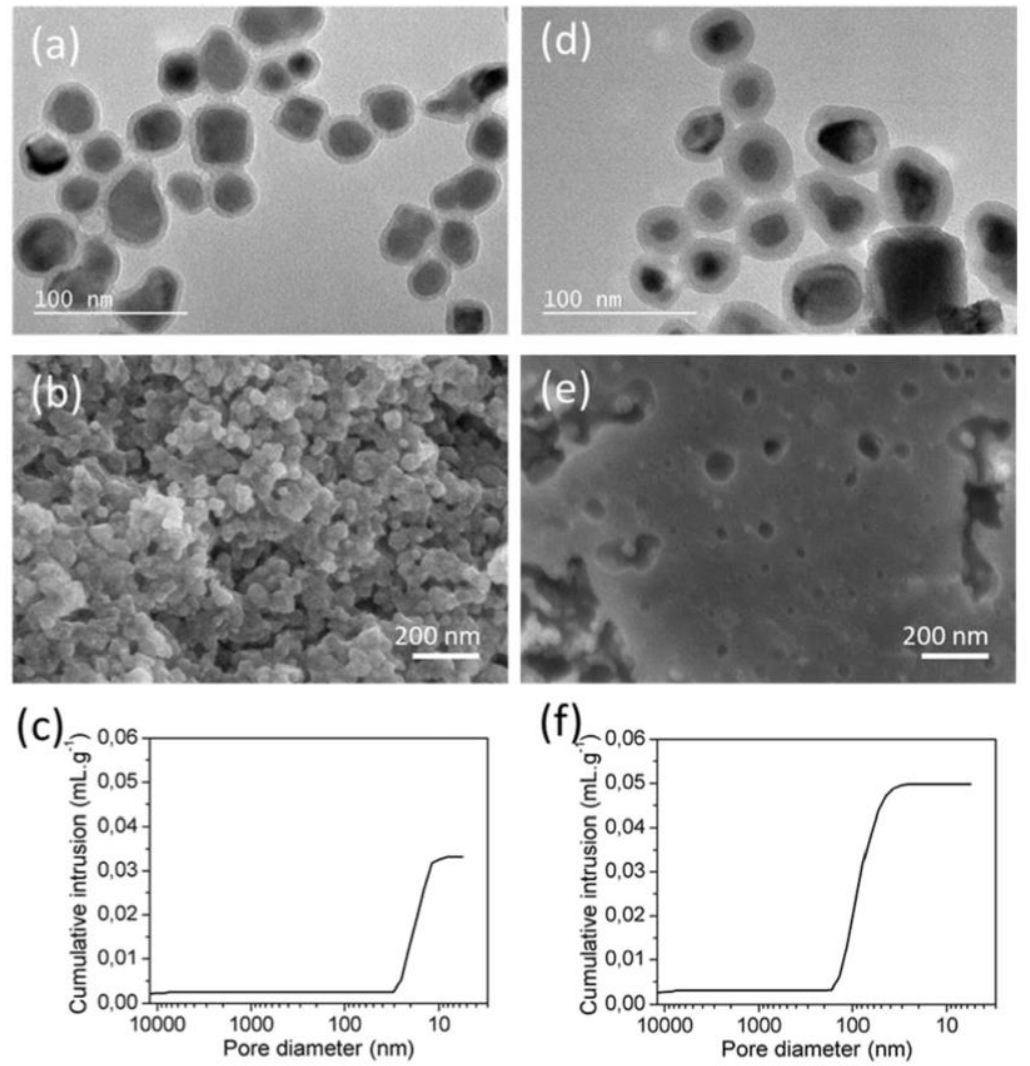

Fig. 2. Transmission Electron Microscopy (TEM) images of a) LSMO@SiO b) $\mathrm{LSMO}_{\mathrm{SiO}}(5)$ and e) $\mathrm{LSMO}_{\mathrm{SiO}}(10)$ composites; Cumulative pore intrusion evolution of c) $\mathrm{LSMO}_{2} \mathrm{SiO}_{2}(5)$ and f) $\mathrm{LSMO}_{2} \mathrm{SiO}_{2}(10)$ composites. 

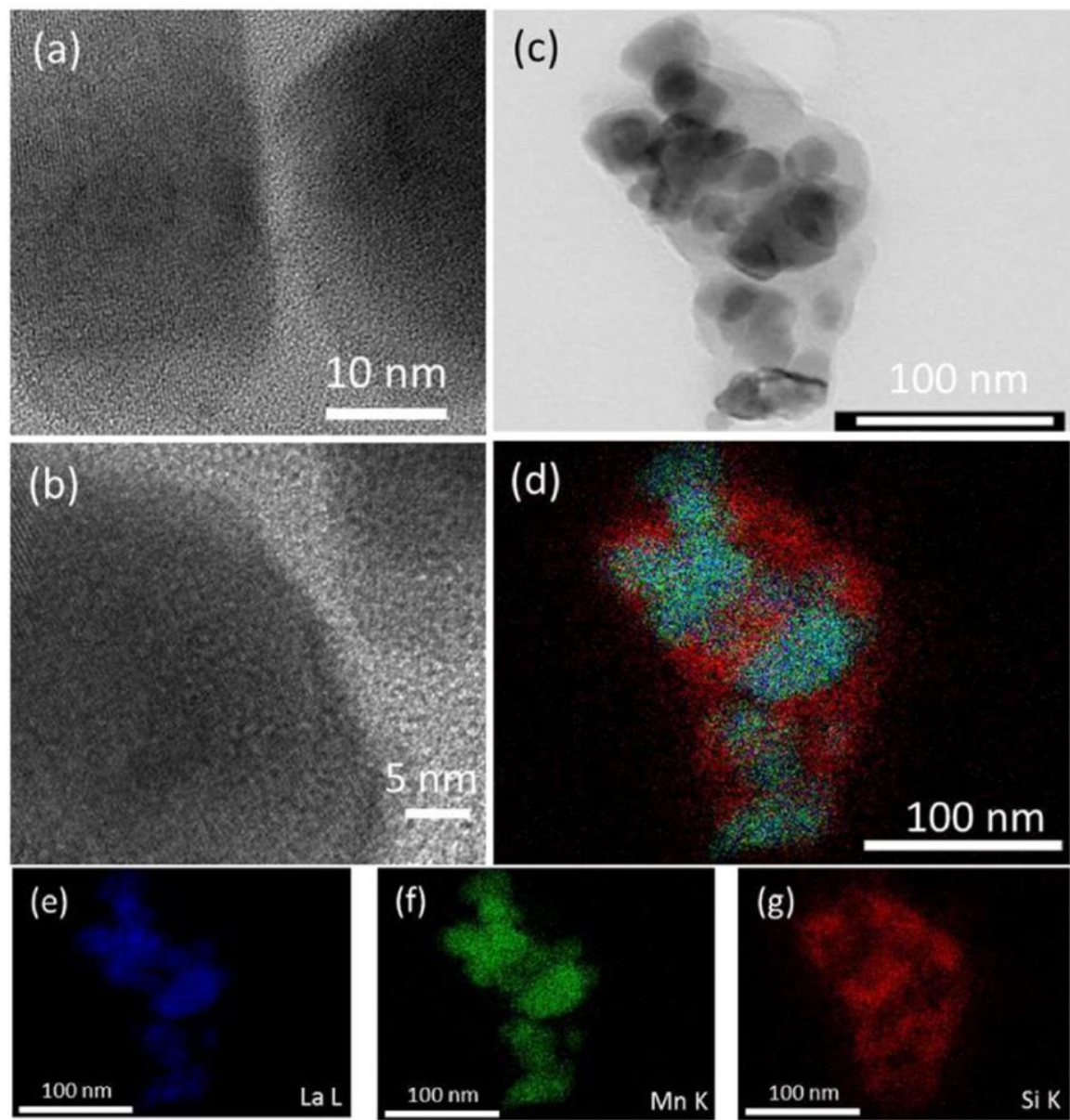

Fig. 3. Characterization of the microstructure of $\mathrm{LSMO}_{\mathrm{S}} \mathrm{SiO}_{2}(5)$ composite with a,b) High Resolution Transmission Electron Microscopy (HR TEM) images, c) bright field Scanning Transmission Electron Microscopy (STEM) image, and STEM-EDS (Energy Dispersive Spectroscopy) elemental maps of d) lanthanum, e) manganese, f) silicon. The image g) represents the superposition of La, Mn and Si elemental maps.
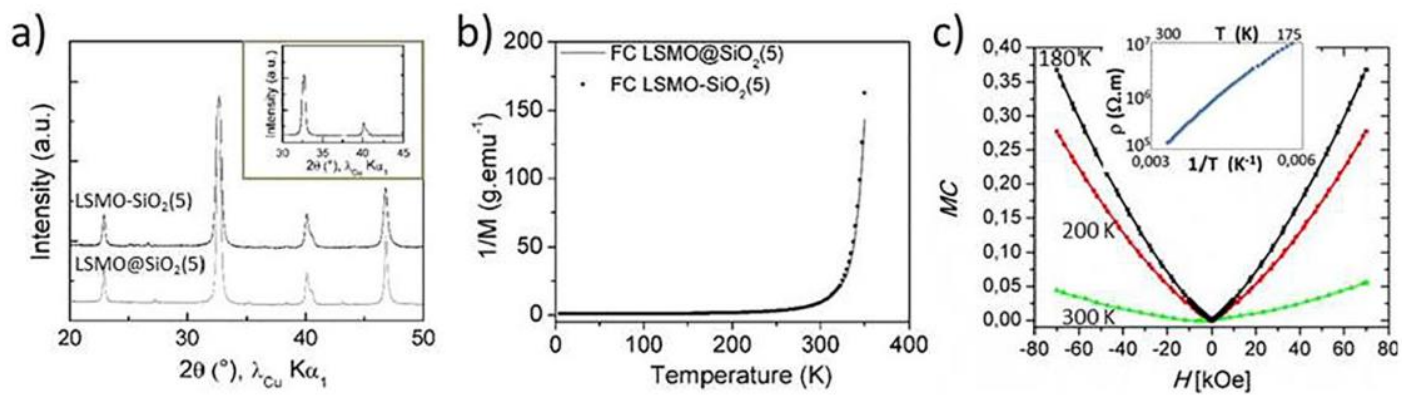

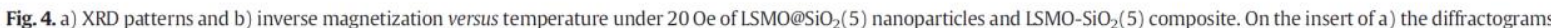

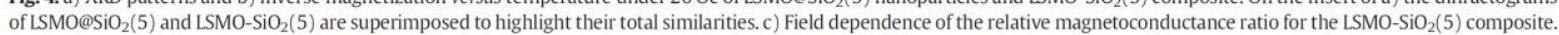
On the insert of $\mathrm{c}$ ), the temperature dependence of resistivity measured on $\mathrm{LSMO}_{-} \mathrm{SiO}_{2}(5)$ under zero field is presented. The resistance of the sample was too high at temperatures below $180 \mathrm{~K}$ 